\title{
Application of Remote Sensing Technique and Geographic Information Science for Flood Risk Mapping-A Case Study of the Offinso District, Kumasi-Ghana
}

\author{
Emmanuel Oduro Amoako* and Lin Sun \\ Geomatics College, Shandong University of Science and Technology, Qingdao, China
}

*Corresponding author: Emmanuel Oduro Amoako, Geomatics College, Shandong University of Science and Technology, Qingdao, China, Tel: 0532-86057276; E-mail: kwasi876@gmail.com

Rec date: January 16, 2018; Acc date: January 29, 2018; Pub date: January 30, 2018

Copyright: (C) 2018 Amoako EO, et al. This is an open-access article distributed under the terms of the Creative Commons Attribution License, which permits unrestricted use, distribution, and reproduction in any medium, provided the original author and source are credited.

\begin{abstract}
Flood disasters have become a menace affecting the socio-economic, environmental, health and safety of the people living within the offinso district of Ghana-Kumasi. Monitoring and mapping out flood prone areas, assessing the extent of coverage is thus not in existence and this has been a problem for the government and the entire emergency agencies.
\end{abstract}

However, this literature uses remote sensing and GIS as an emerging tool within the African Region to address and improve the efficiency of flood monitoring, and mapping with reference to offinso District.

A Landsat ETM+ Remote Sensing Data of 2015 acquired through the GLOVIS website at the time of flooding to make a flood risk map with the help of GIS analysis tools and a generated DEM which shows the topography and elevation of the district.

Keywords: Flood monitoring; Landsat ETM+; GIS; Flood risk

\section{Introduction}

Floods are by far the most destructive natural disasters in the world that destroys lots of lives and property worth millions of dollars. However, according to Jonkman [1], Floods are associated with primary effects such as loss of lives and property, damage to infrastructures, eco-systems, cultural values, roads and bridges, with secondary effects such as outbreak of diseases as well as tertiary effects like loss of soil fertility, famine and poverty. In Ghana, flooding has become a major cause of concern with the most affected area being the Offinso District in Kumasi, Ghana. The floods that hit the country are mostly related to heavy precipitation that mostly last for days. When this happens, most river basins overflow it banks and submerges the surrounding towns as in the case of Offinso District. Some of the major flood disasters which has been recorded in the country over the years are as follows; 1955, 1960, 1963, 1973, 1986, 1991, 1995, 1999, 2001, 2002, 2010, 2011, and 2015 [2,3].

However, the management of flood has always been a problem as the needed technology to make predictions, monitor, give early warning, and map out flood risk areas to mitigate the cause are not in existence. Konadu and Fosu [4] outlined four stages in flood management. These are; prevention and mitigation, preparation, damage assessment, and prediction. This literature uses remote sensing and Geographic Information Science as a new technology for flood risk mapping. This will help policy makers and other Disaster Management Agencies to be able to monitor, predict and evacuate people to a safe place before the flood.

\section{Methodology}

The systematic procedure adopted for mapping out flood prone areas in the Offinso District is spelt out. A Landsat ETM+ images for the year 2015 with $<5 \%$ cloud coverage was acquired from GLOVIS website. These images were radiometrically and geometrically accurate with its spectral bands, (band 1, 2, 3, 4, 5, 6 and 7) stacked together into a single file to produce a color composite image. The shapefile obtained from the topographic map was used to subset the area of study from the stacked image.

A Digital elevation model (DEM) that gives the topography of the land, provides elevation information with the help of ArcGIS tools was used to produce flood risk map. The depressions within the DEM were filled using the sink tool found in ArcGIS.

Flow direction raster was used as an input in flow accumulation to determine the cells within the raster where flowing water will accumulate. Moreover, the outcome flow accumulation raster was classified to generate stream networks. These networks portray the flow of large bodies of surface water in the case of heavy precipitation or when a water body overflows its banks. Streams were extracted at a threshold where flow accumulation is $>=500$ at Offinso. The drainage basins were delineated to locate the flow of water from a particular source. This made it easy for the raster flow direction to be analyzed and find all the sets that are connected to the same drainage basin (Figures 1-3). 
Citation: Amoako EO, Lin S (2018) Application of Remote Sensing Technique and Geographic Information Science for Flood Risk Mapping-A Case Study of the Offinso District, Kumasi-Ghana. J Remote Sensing \& GIS 7: 224. doi:10.4172/2469-4134.1000224

Page 2 of 3

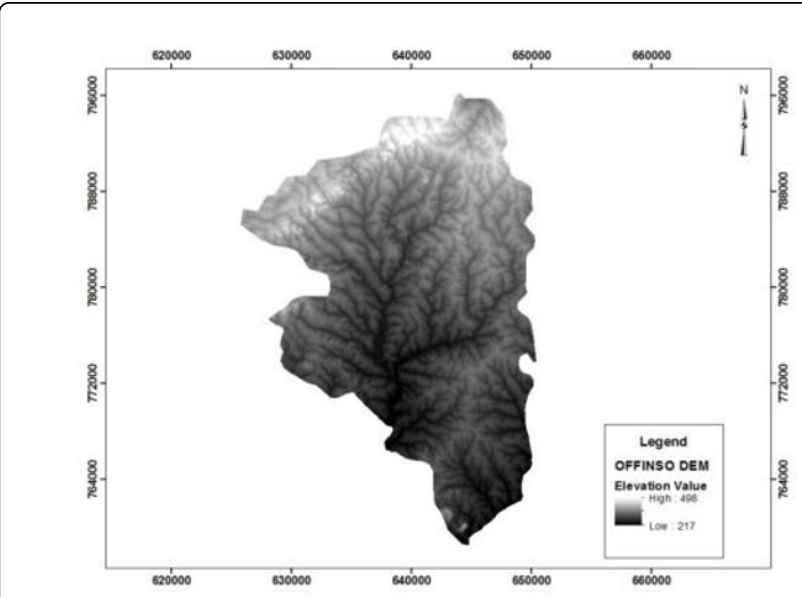

Figure 1: DEM of OFFINSO.

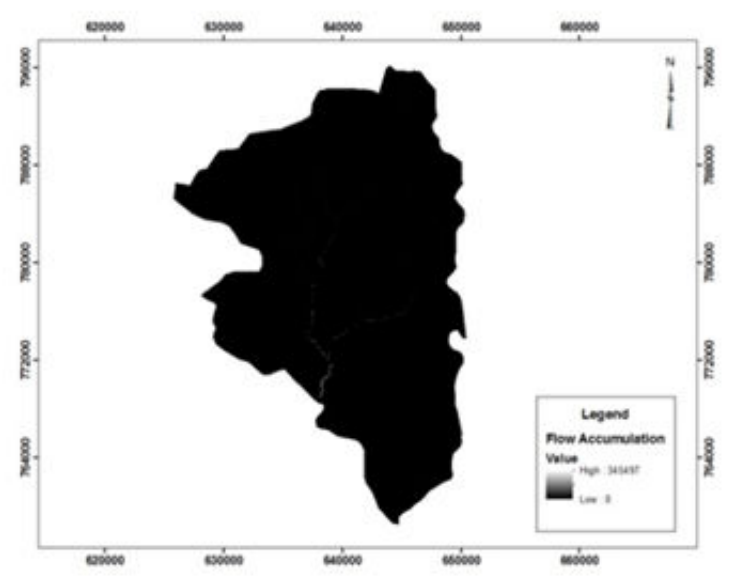

Figure 2: Flow accumulation.

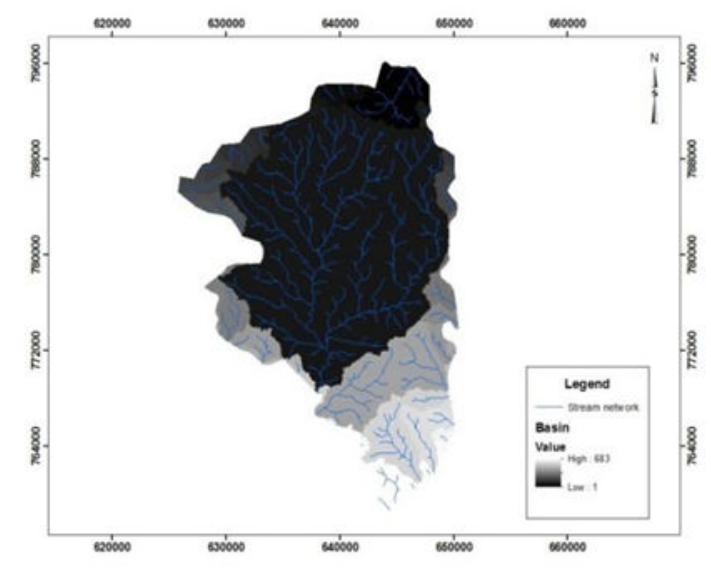

Figure 3: Drainage basins, offinso.
The Normalized Difference Water Index (NDWI) was used to derive possible flood inundation. This algorithm (NDWI) was developed by McFeeters [5], to maximize reflectance of water by using green wavelengths; minimize the low reflectance of NIR by water features; and take advantage of the high reflectance of NIR by vegetation and soil features. As a result, water features have positive values and thus are enhanced, while vegetation and soil usually have zero or negative values and therefore are suppressed [5]. This index was however used to assess photosynthetic activity of vegetation greenness. NDVI was created using band (3), the near infrared and band (2), red of the Landsat images to distinguish vegetative areas from the other land cover classes.

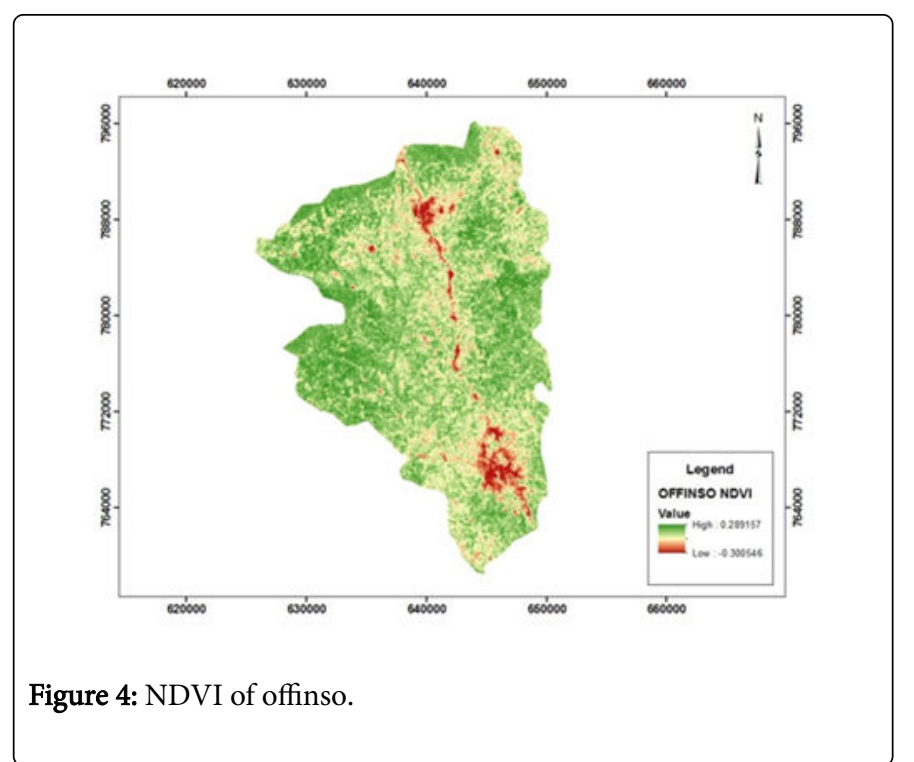

From Figure 4 above, low positive values of the NDVI portrays the existence of sparse vegetation. Negative values of NDVI indicate the existence of water, bare lands or built-up areas. However, based on the NDVI map of offinso in Figure 4, it is evident that a higher percentage of the ground area for Offinso is sparsely vegetated with a higher percentage of bare and built-up areas than vegetation. To identify the class of land cover within flood risk zones, stream buffers were overlaid on NDVI.

\section{Results and Discussion}

A significant factor in determining flood prone areas is steepness of the slope. By overlaying slope on stream buffers, it can be seen that varying slope angles fall within the buffer. All areas falling within the buffer zone are liable to flood. However, in Figure 5, the areas within these stream buffers that are lower than water level are more likely to be inundated when water overflows its bank. This is to say the smaller the slope angle, the closer the surface to water level and the higher the risk. Therefore, areas within buffer zone with low slope are high-risk areas, which are liable to flood, whereas areas within buffer zone with medium slope are medium risk areas and areas within buffer zone with high slope are low risk areas. Therefore, to identify the class of land cover within flood risk zones, stream buffers were overlaid on NDVI. 
Citation: Amoako EO, Lin S (2018) Application of Remote Sensing Technique and Geographic Information Science for Flood Risk Mapping-A Case Study of the Offinso District, Kumasi-Ghana. J Remote Sensing \& GIS 7: 224. doi:10.4172/2469-4134.1000224

Page 3 of 3

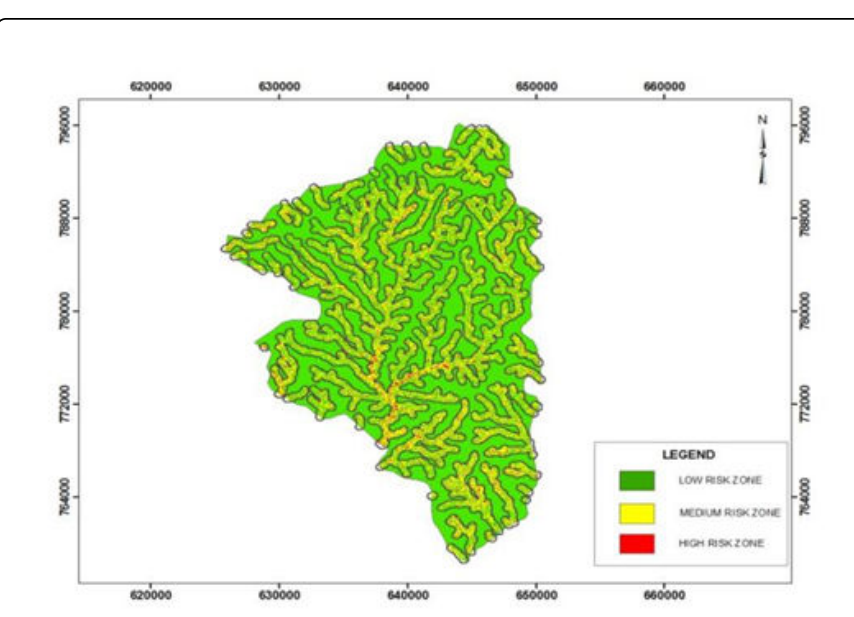

Figure 5: Flood risk zones.

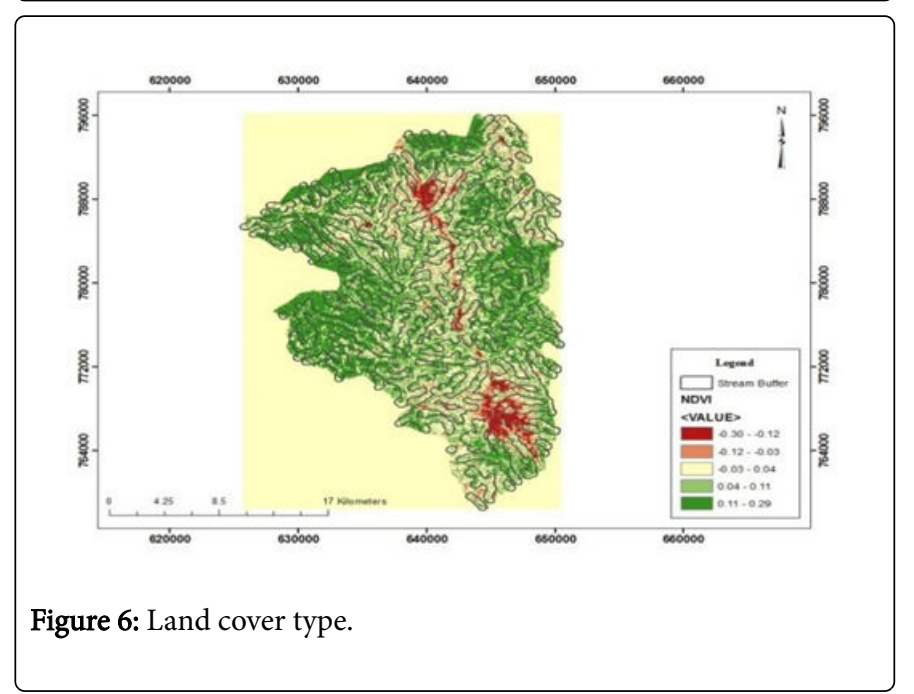

Figure 6 shows the land cover types within the flood risk zones when it was overlaid on the NDVI. Land use and other anthropogenic activities are among some of the reasons of flooding within the offinso district. The different forms of Land use play a crucial role in the event of flooding. The virgin areas or areas that has not been year marked for development with a lot of vegetation cover can absorb the running water when it rains thereby avoiding incidence of flooding. However, with areas marked for development of buildings, roads and pavements there is less or no absorption of rainwater. In Figure 5, the areas with high NDVI values were the undeveloped areas with vegetation cover whiles the developed areas and water bodies were with negative or low NDVI values. The high possibilities of flooding areas are those with negative or low NDVI values whiles those with positive NDVI values are areas which does not record flooding.

\section{Conclusion}

In the above discussion, it is clear that issues of flooding can best be solved with a combination of Geographical Information tools and Remote Sensing Technique. However, the resulting maps has proven that in the unlikely event of flooding, the whole of Offiso District will be liable to flood. Therefore, through this Risk map, decision makers will be able to target the high-risk areas for risk mitigation in order to reduce the impact of flooding in the offinso District. The Flood and risk mapping also makes possible for government and other nongovernmental agencies to categorize the risk factors and allocate resources, build infrastructure, and put in place proper early warning systems to reduce the effect caused by flooding.

\section{References}

1. Jonkman SN (2005) Global perspectives on loss of human life caused by floods. Natural Hazards 34: 151-175.

2. Orok HI (2011) A GIS-Based Flood Risk Mapping of Kano City, Nigeria. MSc Thesis, University of East Anglia, School of Environmental Sciences, University, Plain, Norwich.

3. Kwang C, Osei EM (2017) Accra Flood Modelling through Application of Geographic Information Systems (GIS), Remote Sensing Techniques and Analytical Hierarchy Process. J Remote Sensing \& GIS 6: 191.

4. Konadu DD, Fosu C (2009) Digital Elevation Models and GIS for Watershed Modelling and Flood Prediction - A Case Study of Accra Ghana.

5. McFeeters SK (1996) The use of normalized difference water index (NDWI) in the delineation of open water features. Int J Remote Sens 17: 1425-1432. 